\title{
New Methods for Collaborative Experiential Learning to Provide Personalised Formative Assessment
}

https://doi.org/10.3991/ijet.v14i07.9173

\author{
Abhishek Bhati $\left({ }^{\varpi}\right)$, Insu Song \\ James Cook University, Singapore \\ Abhishek.bhati@jcu.edu . au
}

\begin{abstract}
Supporting diverse and rapidly changing learning styles of new digital age generations is one of the major hurdles to higher education in the age of massification of education markets. Higher education institutions must now utilize unprecedented network speed and mobile technology to create stimulating learning environments for new digital age generations. This paper presents a new learning and teaching model that combines dynamic learning space (DLS) and mobile collaborative experimental learning (MCEL) for supporting diverse learning styles of students. DLS assists students with stateof-art modern wireless network technologies in order to support fast-paced, multi-tasking, data and content intensive collaborative learning in class. The model further extends student learning activities beyond classroom by allowing students to continue their learning anywhere and anytime conveniently using their mobile devices. MCEL provides automated continuous personalized formative-feedback 24/7. The main objectives of the model are to improve student engagement and to provide ownership of their learning journey, experiential learning, contextualized learning, and formative assessment at low cost. The model employs three factors that influence collaborative experiential learning and formative assessment. The three factors are:

- The use of learning space within the classroom

- Wireless learning technology

- Mobile learning system (m-Learning)

Pilot studies of the model are conducted and evaluated on two groups of postgraduate students. Their participation is observed, and a survey is conducted. The results show that (1) DLS encourages high-level learning and diverse learning styles to move away from passive low-level knowledge intensive learning activities; (2) MCEL supports Bigg's constructive alignment in curriculum design, contextualized experimental learning, and personalized formative learning.
\end{abstract}

Keywords-Mobile learning, collaborative learning, experiential learning, dynamic learning space, formative assessment. 


\section{$1 \quad$ Introduction}

In the age of massification of education market, all educational institutions must now accommodate changing student profiles and diverse student populations through technological and pedagogical advancements [1]. Institutions need to accommodate diverse learning styles and preferences of students often comprising working professionals, different age groups, and culturally diverse groups. For instance, in science learning, a typical laboratory setup would expect students to replicate the results of certain experiments done by previous scientists, such as creating oxygen, setting up computer networks, and implementing software functions for sending SMS messages. However, not all student projects can have clear and direct outcomes to measure against the outcomes of students. For example, designing a more fun and engaging interaction for an interactive product for travel sector can be more challenging and time consuming to assess. In both cases, however, the main challenges are stimulating students, facilitating effective learning, extend learning beyond classrooms within limited resources.

Researchers have been trying solve these challenges through flexible learning [1] [2] [3] and blended learning [4] approaches. Faced with new digital age generations [5], young learner [6], unprecedented network speed and mobile technology, education researchers now frequently quote mobilized curriculum [7], socialinteraction oriented learning [8], personalized learning [9], online community [10] and collaborative mobile learning [11] in their studies. These previous studies suggest that collaborative learning spaces and mobile learning approach hes can be used to create learning environments that can stimulate students, facilitate effective learning, and extend learning beyond classrooms by providing personalized learning more efficiently.

However, these studies have focused mainly on re-designing curriculums taking advantage of mobile technology, and improving communication and access to learning contents. In this paper, we focus on exploring "how" mobile devices can be used to create collaborative experiential learning environment in education. We envision that mobile learning can allow students to access simulated learning laboratories anywhere any time through mobile devices, providing experiential and contextualized learning in digital space, and formative assessment through continuous feedback from the simulated lab. The objectives of this new research direction are to

- Improve student engagement

- Provide ownership of their learning journey

- Provide experiential, contextualized and formative assessment at low cost.

To achieve these goals, a new combined teaching and learning model based on Dynamic Learning Space (DLS) and Mobile Collaborative Experiential Learning (MCEL) has been developed using design-based research approach [12]. DLS uses Wireless Learning Technology (WLT) to provide flexible learning space.

MCEL combines service-orientation design paradigm and context-free grammar parser to provide easy to use curriculum development platform and natural-language- 
based user interaction. Teachers can express learning contents and objectives using event-condition-action rules and students can interact with MCEL using structured SMS message. A pilot study was conducted to evaluate the effectiveness of MCEL. The evaluation results show that MCEL is usable, students' learning activity continued beyond classes, students received feedback anywhere anytime, and they felt sense of ownership of their learning journey.

The paper introduces the two methods respectively and is organized as follows. In Section 2, we identify gaps in current studies by reviewing literature on dynamic learning spaces for improving social interactions, mobile learning, mobilized curriculum, formative assessment, and enhancing social experiences. Section 3 summarizes learning types, research methodologies, and evaluation approaches. Section 4 details the pilot study and evaluation approach that are designed based on the literature review. In Section 5, the evaluation results are reported. Section 6 concludes the paper with remarks.

\section{Background}

This work is based on m-learning, collaborative learning, social interaction in learning, mobile technologies, service-orientation design paradigm, and natural language parsing. The following sections provide a brief overview of the core techniques, focusing on developments of flexible learning approaches, mobile learning for mobilized curriculum, formative assessment, and enhancing social experiences.

\subsection{Motivations of flexible learning}

Starting from Bloom's taxonomy [13][14][15], existing literature clearly encourage various forms of blended learning to better support the changing student profile. Bloom's taxonomy broadly classifies educational learning objectives into three psychological domains: Cognitive (knowing), Affective (Feeling), and Psychomotor (Doing). This Bloom's taxonomy stimulated research on evaluation approaches and reflection on their effectiveness, and helped teachers guide their students to higherlevels of the taxonomy for deeper level of learning.

Bloom's taxonomy was further revised by other researchers in to levels of learning [16] [17], which are now frequently stated in graduate attributes and learning outcomes of Australian tertiary education. It provides a benchmark, against which an educator can measure a student's level of understanding. The six levels of learning (remember, understand, apply, analyse, evaluate, and create) cannot be achieved by simply standing in front of students and delivering lectures in classes. Due to recent developments in internet-based communication technologies, and interactive media authoring tools, educators can now enrich the student learning experience and impact of learning by combining the variety of educational tools and technologies available to them. 
Kolb's Learning Cycle [18] provides a learning model to address different learning styles similar to Felder's learning model [19]. It places students within one of four cycles based on two preference dimensions: why, what, how, and what if. Therefore, it is recommended to teach around the circle by starting in the "why" cycle and ending in the "what-if" cycle to address all learning styles.

The 3P model of teaching and learning [20] encourages high-level learning through constructive alignments guided through the three teaching and learning activities: please (motivate and contextualize), process (learning focused activities), and product (assessment of learning outcomes). As students learn what they think they will be assessed on [21], the assessment tasks should mirror the desired learning outcomes and the teaching and learning activities should be directed towards the same desired learning outcomes.

The 5E approach of instruction model [22] [23] has been used in science education to provide a rich environment for doing science. The approach was adopted in Australia (e.g., Primary Connections teacher-professional learning program) and trialled in 56 schools in year 2005. The approach follows inquiry-based learning [24] using open investigations, cooperative learning, integration of assessment with teaching and learning. The objective is to encourage teachers to be facilitators of the processes of science in a sequence of teaching and learning activities: engage, explore, explain, elaborate, and evaluate.

The advancements in new internet-based educational technology now ask us to rethink pedagogy or even to reinvent the art of science of pedagogy [25][26] as digital technology provides a new context for learning.

\subsection{Dynamic learning space: wireless learning technology \& spaces of learning}

Wireless Learning Technology (WLT) in education includes the subsets of mobile technologies as well as the WLTs systems used in new 'networked' classrooms. Thus, the broad term WLTs encompasses the use of mobile devises such as handheld smart phones, tablets and laptops; WLT platforms installed in fixed spaces such as classrooms using Wireless LAN (WiFi); as well as the use of mobile technologies connecting to classroom WLT platforms. Each of these technologies has formed an active area of research within the teaching and learning arena. The following literature review sets out the broad range of WLTs and approaches to understanding their importance to the future direction of education.

\subsection{Mobile wireless learning technology (WLT)}

Mueller et al. [27] studied the use of mobile (handheld) devices in higher education. Conducted at one university over one teaching period of sixteen weeks, the researchers documented students' use of one mobile technology, that of the smart phone, in a designated undergraduate subject. Students reported that the smart phone device was easy to use, and they were optimistic regarding its potential role as an instructional tool. The findings indicated that students were self-directed in their use 
of the device, building their capacity as both interdependent (collaborative) and independent (individual) learners. The students explored smart phone functions and uses beyond the tasks provided by their instructors. They found innovative ways to use the smart phones within and outside of the classroom. Exchange of information and ideas emerged as the single most frequent use of the smart phones. Findings recognized that academic staff need to ensure that clearly defined instructions for the use of smart phones as teaching devices are communicated and explained to students [27].

It is important to note, however, that although the study supported the use of a handheld device as a learning tool, their use as a "classroom instructional" device for learning and teaching purposes was more limited than student-directed use of the device for social communication (chatting and texting) in and out of the classroom [28]. This study highlighted that the affordances of technology are dependent on high student uptake. Absence of student interest and motivation in the use of technology for learning will reduce the intended positive outcomes of the technology. The researchers suggested that student participation in identifying device uses for learning and teaching purposes increases student participation with the mobile devices [27].

Similarly, Ross et al. [29] discuss the positive influences of wireless technology on learning experiences in education. Although this study was conducted in the context of a secondary school, it nevertheless has implications for higher education. The study employed a qualitative methodology of interviews to explain the use of new technology tools, such as the iPad, within the school curriculum. Findings indicated that the use of the tablet devices improved the efficiency of teachers and the workflow of students with neither group constrained by time or space. Students reported being able to use multiple functions and applications of the iPad, namely: writing memos, calculating, and online information searches. For teaching staff, the device promoted technology leadership and efficacy - augmenting their ability to lead a technologically advanced teaching and learning space. Wireless technology tools, including tablets and smart phones, were identified by participants as "remarkably fashionable". Students and teachers were eager to use them, thus changing their worldview of learning and teaching. The authors maintain that exponential growth and adoption of wireless tools will shape learning and teaching practices in the near future. The availability of high-speed internet connection will be a primary factor in the efficient and effective use of this technology.

Morgan et al. [30] explains how mobile learning can be enriched by utilizing audio-visual methods of communication coupled with the technological facility to communicate. Referring to student engagement in education, Morgan deliberates on the use of handheld wireless devices such as laptops, tablets and smart phones. This study explores the additional utility of using mobile devices with publicly available applications such as mind mapping software and the WIKI collaborative platform. It reveals the popularity of social media platforms to further enrich the quality of mobile learning facilities.

Findings from the above studies suggest that mobile technologies in educational spaces are highly useful. This is primarily due to the quality returns from the devices 
utility; specifying, effective and efficient communicative methods are enriched by the technologies' convenient accessibility in time and space.

With respect to the introduction of on-line education in courses offered in Singapore, Koh et al. [31] identify certain benefits of wireless learning technology: motivation for student learning enhanced capacity for assimilation of knowledge, and greater knowledge retention of the subject matter. The researchers make reference to increases in motor coordination which arise due to stimulation caused by the activity of on-line game playing. They further explain 'push factors', which refer to the external forces influencing the utility of gaming; as well as 'pull factors', which refer to the internal motivating factors that stimulate teachers to utilize gaming in the field of education.

Tay et al. [32] highlight the positive influence of learning with technology, referring to it as 'ease to learn'. These researchers conclude that the use of web 2.0 online social applications, in conjunction with open-source learning management systems, can be highly beneficial. They contend that success is due to the nature of the collaborative activities and teaching experiences that are derived when these technologies are put into practice.

However, the need for caution over the over-zealous and under-analysed take up of wireless learning technology has been noted by Gay et al. [33]. The authors warn that wireless technology for educational purposes cannot be adequately understood and adopted through a one-size-fits-all mentality. They argue that different learning and teaching environments, course content, pedagogical models and curricular philosophies influence how wireless technologies can be used most effectively.

At this time of rapid change, both technologically and pedagogically, the paper by Gay et al. [33] is a sobering reminder of the importance of an integrative matrix for the analysis of new 'networked' spaces of learning. Such a thinking matrix involves the simultaneous consideration of philosophy, learning and teaching practice, learning space design, and wireless learning technologies - both mobile technologies and WLTs platforms.

\subsection{WLTs \& spaces of learning}

In recent years, there has been a paradigm shift from the traditional teacheroriented to a more interactive, student-oriented, higher education environment. Engagement with, and participation of, students is prioritized, with teachers encouraging students to use familiar technology as part of their learning experience. While many new audio visual and IT related products have been developed to meet this demand, no one product has met all the needs of the contemporary classroom as effectively as Wireless Learning Technologies. Newly designed classrooms use a combination of students' individual mobile WLT gadgets with LCD screens connected to keyboards, computer consoles, WLT platforms, and Wireless LAN (WiFi).

In a recent case study of a WLT classroom in Hong Kong, Salter, Thomson, Fox and Lam [34] evaluated the implementation of prototype technology-rich collaborative classrooms at the University of Hong Kong (HKU). The learning spaces 
were designed as a retro-fit of an existing studio. Through the development of collaborative learning spaces, the University hopes to provide an enhanced learning and teaching environment for both staff training - including training in teaching in the new space - and student learning.

The Salter et al. [34] team utilized an outcome-based approach to student learning (OBSL) to promote creative teaching methods and activities to meet learning objectives. The study reports positive feedback from the majority of students pertaining to the use of technology and collaborative interaction in the learning spaces.

\subsection{Mobile learning for enhancing social experiences}

One primary goal of educators is creating a harmonized environment where students could construct their learning upon both physical and social contexts augmented on the learning content. Therefore, social interaction is considered as the key advantage and ingredient in the designs of mobile learning practices. In particular, some researchers viewed that mobile learning could enable students interact with peers, teachers, and subject contents more efficiently and unobtrusively [8]. Furthermore, [11] proposed that mobile-learning can provide efficient collaborative learning environment to enhance in-class learning experiences. On the other hand, [8] proposed a curriculum design practice, called interwoven learning interactions, for creating more socially interactive learning environments.

\subsection{Mobile learning for formative assessment}

In education, competency assessments are typically assessed summatively due to the unique curriculum design in this sector. In a similar reason, not much research has been done in the use of mobile learning in education. Furthermore, the use of mobile technology in education initially met with scepticism [6]. Elsewhere, Kneebone and Brenton [35] reported that the usage of mobile devices did not improve the quality of assessment tasks or even reduced efficiency. Other studies even suggested that special types of mobile devices were required to solve these problems [36].

However, Coulby, Hennessey, Davies, and Fuller [37] suggested that identifying an appropriate use of mobile devices is key to solving the problems. They hypothesized that m-learning could be used to conduct formative assessment in competency assessments in education. This was an important observation as competency assessments were typically assessed summatively in education.

In a similar attempt, but independently, McIntyre [38] studied use of mobile technology by management students. The study findings acknowledged that students generally positively motivated towards 'mobiles' as social and personally integrated lifestyle and organisational aids. They argued that awareness of constant communicability, conspicuous technology consumption, solipsistic, diversionary and 'lazy' learning drawbacks were the key negative attitudes towards Mlearning due to the extensive use of mobiles as learning facilitators. The researchers designed a new learning experience and incorporated defined limits around various elements of 
technology within a UbiComp environment relating to social, study or work technology utility (tec-utility) zones with only limited crossover zones of tolerance. The research findings suggested that controlled environment has better outcomes.

\subsection{Mobilized curriculum}

Zhang et al. [7] developed a methodology for re-designing existing curriculums into mobilized curriculums. The mobilized curriculums were designed to allow students to participate in inquiry-based learning in class or out of class using their mobile devices. The authors hypothesized that mobilized curriculums, referred to as "mobilized lesson" by [39], might be able to provide an infrastructure that fosters student-centred learning due to the pervasive nature of mobile technologies. Students would have 24/7 accesses to the mobile devices to participate in both informal and formal learning in class or out of class. They reported that there were significant changes in students' learning behaviours. Students engaged in more collaborative learning with peers and teachers, asked more questions, and became more creative.

On the other hand, Song et al. [9] proposed a design process for creating a mobileassisted personalized learning environment within Kolb's experiential learning model [18]. The authors viewed that the mobility of learners enabled by mobile technologies would allow learners personalize both their learning goals [40] and context [41]. To overcome the limitations of experiential learning, the researchers incorporated goalbased approach [42] into their mobile-assisted personalized learning environment to provide sustained experiential learning experience for science education.

\subsection{Technologies for automating assessment}

Now, over $87 \%$ of the global population and $79 \%$ of developing world's population has access to Simple Messaging Service (SMS). This pervasiveness of mobile technologies has created both challenges [35] and opportunities [37]. As seen in previous sections, we are still learning how to integrate these new technologies. In particular, we need to develop platforms for designing curriculums, methodologies for re-designing existing curriculums [7], and automated methods for providing formative assessments [37]. One particular technology that has been proven to be intuitive and efficient in capturing and implementing business requirements in business process automation is event-condition-action (ECA) rules. ECA is the basis of event-driven architecture (EDA) pattern adopted by SOA (Service-Oriented Architecture) 2.0 for more natural modelling of business processes. ECA can be converted into Business Process Execution Language for Web Services (BPEL) [43], allowing an easy migration between different modelling tools. BPEL is supported by major business process management software and development tools (e.g., Eclipse IDE).

Formal language processing [44] has been proven efficient and effective in processing structured languages, such as formulas and statements of programming languages. Its advantage over natural language processing [45] is their reliability and accuracy, which are very important usability aspects. Re-searchers can now build 
custom grammars using lexers and parsers (e.g., ANTLR [46]) defined using simple rewrite rules to automatically process structured SMS messages.

\section{Types of Research Methodologies and Methods Utilized in M- Learning Research Papers}

Table 1 summarizes learning types, for which m-learning researchers tried to integrate mobile technology into teaching and learning. It shows that mobile technology can be applied to most of learning environments, such as in-class, out-ofclass, and inquiry-based learning. It also showed that m-learning were applied to new emerging learning types as well, such as personalized learning, mobilized science curriculum, and social-interaction oriented learning. Table 1 summaries research methodologies and evaluation approaches used by m-learning researchers. It shows that pilot studies utilizing observation, interviews, and questionnaires data gathering approaches were commonly employed to evaluate their proposed methods.

Table 1. Learning Types and Research Methodology and Evaluation Approaches

\begin{tabular}{|l|c|}
\hline \multicolumn{1}{|c|}{ Learning Types Supported } & Literature \\
\hline Project-based or Inquiry-based learning & {$[7][8][9]$} \\
\hline In-class learning & {$[7][11]$} \\
\hline Out-of-class learning & {$[9]$} \\
\hline Personalized learning & {$[9]$} \\
\hline Curriculum design: A methodology for designing mobilized science curriculum & {$[8]$} \\
\hline Interwoven learning interactions & {$[8]$} \\
\hline Social-interaction oriented learning & {$[37][47]$} \\
\hline Formative Assessment & {$[11]$} \\
\hline Collaborative learning environment in classroom & Literature \\
\hline \multicolumn{1}{|c|}{ Evaluation Approaches } & {$[7][8][11]$} \\
\hline Curricular materials in classroom settings & {$[9][11]$} \\
\hline Design-based & {$[37]$} \\
\hline Pilot formative assessment & {$[47]$} \\
\hline Pilot training & {$[47]$} \\
\hline Ellaway's [48] descriptive framework of e-learning & {$[47]$} \\
\hline David et al's [49] contextual mobile learning approach & {$[50]$} \\
\hline Student Perceptions on m-Learning & \\
\hline
\end{tabular}

These previous studies suggest that m-learning can be used to create learning environments that can stimulate students and facilitate effective learning by providing personalized learning more efficiently. However, these approaches mainly focused on re-designing curriculums taking advantage of mobile technology, and improving communication and access to learning contents. 


\section{$4 \quad$ Research Methodologies}

This paper employs a range of methodological consideration. The methodology is organised into two sections. The first section outlines the research approach to study WLT and dynamic learning spaces.

\subsection{Wireless learning technology \& collaborative learning spaces}

Participant observation is the primary research method adopted to analyse the learning space of the classroom. Participant observation technique is useful in seeking deeper insights on the research subject matter [51]. The researcher in this study entered a scheduled class and took notes based in the classroom based on the observation. Photographs of student interaction were taken to provide context to discussion. A survey of the literature [51][52] reveals good examples of the use of photographs as a research instrument in drawing attention and providing focus to the research study [53].

Purpose built and designed 'networked' spaces of learning across its three tropical campuses: [omitted for de-identification of the manuscript]. Similar to HKU, the new model classrooms at our campuses have been retrofitted. Currently the campus has two technology enhanced collaborative learning spaces. One uses Apple WLT and the other uses the ProVEOS WLT system developed by the Singaporean company WOW Vision. The second room is outlined here.

The learning space is rectangular with two doors along one length of the room and a bank of windows along the opposite wall. The room consists of six tables that jut out from the four walls like rectangle satellite-isles. Six chairs on rollers are arranged three either side of each table. Above each table hangs a large 40-inch LCD screen it is wire connected to a keyboard and mouse, which rests on the table's surface. Across the breadth of two walls of the room run long whiteboards. The new 'networked' room is covered with a designated Wireless LAN (Wi-Fi) which students and academics can connect to using their mobile devices in order to project their work wirelessly on the LCD screen. However, not all mobile devices are compatible with the ProVEOS wireless learning technology. For instance, the installed WLT system does not support iPad. As all fulltime students and academics are issued with iPads at the campus, this non-compatibility is a problem. Laptops and smarts phones are compatible. Alternatively, the keyboard and mouse attached to each LCD screen allows a 'designated driver' at each table to edit work directly on the screen with input from the student team. The room is well lit from the bank of windows installed at table level, blinds soften the tropical sun, and combined with the monochromatic grey-scale of the room, allows the space to feel light and airy. This sense of space is enhanced by the view out of the window. The room is on the third level and a glance outside takes in the tops of clumping palms. 


\subsection{M-learning system \& automating assessment}

The section explains the methodology adopted to study M-Learning System \& automating assessment. MCEL is developed and evaluated using design-based research approach [12]. The initial prototyping is done using wizard-of-oz prototyping, in which human instructors simulate the automated system using structured instructions and rules. After the usability and technical feasibility problems are addressed, the system is implemented on an Android tablet.

Figure 1 shows the overall system diagram of MCEL, which is a simulated lab running on an Android tablet. It can continuously interact with students in order to deliver personalized assessment via simple text messages. The learning script is formulated based on Event-Condition-Action (ECA) paradigm, which is now adopted by SOA (Service-Oriented Architecture) 2.0. This approach will provide more natural modelling of business processes. ECA can be converted into Business Process Execution Language for Web Services (BPEL) [43], allowing an easy migration between different modelling tools. BPEL is supported by major business process management software and development tools (e.g., Eclipse IDE). An Android tablet with Android OS v3.0 is used to host the simulated lab. ANTLR [46] is used to generate simple lexer-parser Java-code for our structured SMS messages.

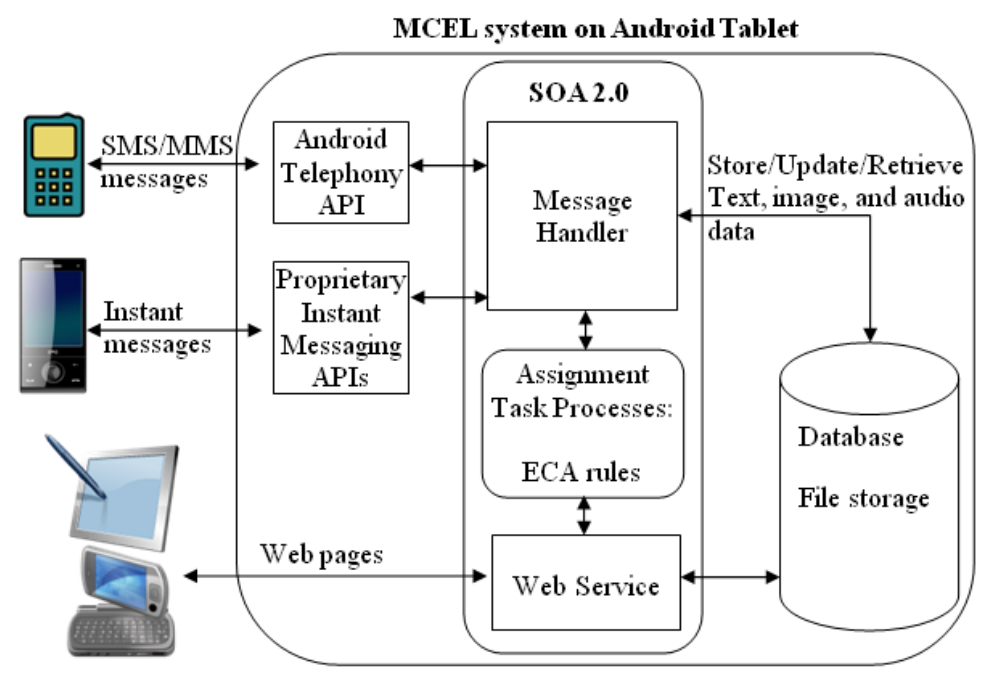

Fig. 1. Mobile Collaborative Experiential Learning (MCEL) System

The resulting MCEL developed through the design-based research approach [12] is evaluated. For the evaluation, a learning script for two questions was prepared. Students were told that an automated system will guide their learning by interacting with them through simple text messaging services. Survey questions were designed based on previous mobile education studies done by Nokia in 2008. Three sets of questions were selected from the question set used by these previous researchers:

- User-friendliness 
- Technical feasibility

- Cost effectiveness

The survey was designed to investigate if MCEL would improve learning experience, and it would be usable (effective, efficient, and enjoyable to use), technically feasible, and cost effective.

This study was approved by JCU Human Research Ethics Committee (Approval ID H5402). Participants were be recruited from students who are studying at JCU Singapore campus. First the participants were given detailed description on the project, their rights, information sheet and consent form. Once they signed the consent form, they were given information on the tasks to complete. The tasks varied depending on which subject they are undertaking. For example, problems were given to students enrolled in Management subject and the problem in Event Management were provided to students enrolled to Conference and Event Management subject. Each task took less than 20 minutes and no more than 2 tasks were given to each participant. The students were allowed to complete the tasks anytime anywhere. Once the participants have completed the evaluation, they will fill in the questionnaire. After the questionnaire, an informal interview session was held and students provided their experience of using the prototype. The participants were then thanked and provided with small tokens of appreciations.

\section{$5 \quad$ Experimental Results}

\subsection{Dynamic learning space}

During our trial of DLS, the active interaction with fellow classmates and the facilitator in the classroom provided immediate formative feedback and enhanced learning experience. In addition, the use of technology and smart devices facilitated access to information and enriched the discussion. Unlike conventional teacher oriented and teacher directed classrooms, students were able to move between groups to form various sizes of groups spontaneously based on their topics of interest. Mobile WLS allowed them to connect to one of the displays near a group to share information with the group members. Students were able to exchange their ideas with rich multimedia aids, such as texts, audios, images, and videos. This allowed students to contribute to discussions and problem solving spontaneously and in many different ways. Instead of relying on recall of text book or lecture materials, students demonstrated creativity in constructing their solutions through information sharing using various methods, such as demonstration, visualization, role playing, and including conventional form of discussions.

Like the Hong Kong case study, the new '-networked' classrooms at JCU Singapore are still being trialled and academics are still discovering the affordances of these spaces of learning - both spatially and technologically. The observation suggests that DLS encourages high-level learning moving away from passive lowlevel knowledge intensive learning activities. It also supports diverse learning styles 
through blended learning [13][14][15]. Students exercise Cognitive (knowing), Affective (Feeling), and Psychomotor (Doing) through verbal communication, drawings on iPads, text messages, and electronic documents. It clearly shows that DLS can encourage these forms of blended learning to better support the changing student profile.

\subsection{Mobile ccollaborative eexperiential learning}

Table 2 show the survey results of MCEL. Most of the participants viewed MCEL useful (user-friendly both in learning and technical accessibility) and cost effective.

Table 2. Perceived Usefulness, Usability, Technical Feasibility, and Cost-effectiveness of Students

\begin{tabular}{|l|l|c|}
\hline \multicolumn{1}{|c|}{ Question No. } & \multicolumn{1}{c|}{ Questions } & \multicolumn{1}{c|}{ Rating } \\
\hline \multicolumn{4}{|c|}{ Atudent user-friendliness (5-point Likert scale response: (1-Strongly Disagree, 2-Agree, 3-Neutral, 4- } \\
\hline U1 & It was easy to use the equipment in this mobile learning course & 4.14 \\
\hline U2 & This mobile learning experience was fun & 4.29 \\
\hline U3 & $\begin{array}{l}\text { According to my experience I would take another mobile } \\
\text { learning course if relevant to my learning needs }\end{array}$ & 4.43 \\
\hline U4 & $\begin{array}{l}\text { I would recommend mobile learning as a method of study to } \\
\text { others }\end{array}$ & 4.29 \\
\hline U5 & Mobile learning increases the quality of e-learning & 3.86 \\
\hline U6 & Course learning objectives can be met by mobile learning & 3.43 \\
\hline U7 & $\begin{array}{l}\text { Communication with and feedback from the tutor in this course } \\
\text { was easy }\end{array}$ & 4.29 \\
\hline U8 & $\begin{array}{l}\text { Mobile learning may be convenient for communication with } \\
\text { other course students }\end{array}$ & 4.14 \\
\hline Technical feasibility (5-point Likert scale response) & 4.14 \\
\hline T1 & Navigation through the mobile learning course was easy & 4.57 \\
\hline T2 & $\begin{array}{l}\text { For mobile learning to be effective it is necessary to use } \\
\text { graphics and illustrations }\end{array}$ & 4.14 \\
\hline T3 & $\begin{array}{l}\text { Evaluation and questioning in the mobile learning course was } \\
\text { effective }\end{array}$ & 4.00 \\
\hline Cost effectiveness (5-point Likert scale response) & Mobile learning increases access to education and training \\
\hline C1 & $\begin{array}{l}\text { The cost of communicating in the mobile learning course with } \\
\text { the tutor and other students was acceptable. }\end{array}$ & 4.00 \\
\hline C2 & \multicolumn{2}{|l|}{4} \\
\hline
\end{tabular}

Some students sent replies even at midnight, clearly showing evidence of their interest and engagement. Out of 22 participants, 6 students completed the questionnaires. The survey results demonstrate that most of the participants viewed MCEL useful: user-friendly in terms of both learning and technical accessibility and cost effectiveness.

The following comments made from the participants also illustrate that MCEL could provide new learning experiences. In particular, students felt that they can take the learning on their own personal pace:

"It is really useful to do answers in our own convenient time \& it was new and attractive to do." 
"Sometimes, type in the correct format is not easy, when the wrong format sending, the cost has already happened, but the communication is no useful this moment."

"Typing answers with mathematical operators took time. But the experience was good."

The survey results and our observation suggest that MCEL supports Bigg's constructive alignment in curriculum design [53], contextualized experimental learning, and personalized formative learning.

\section{Conclusion}

The study identified a gap in the current literature and proposed a new approach for providing more engaging teaching and learning model. The new model makes use of new emerging technologies such as networked classrooms and mobile technologies to create dynamic and creative learning spaces in class and provide continuous personalized formative feedback extending beyond classrooms at much reduced cost. The proposed model can be supported with many available off-the-shelf systems allowing education institutions to create more engaging and vibrant learning environment for diverse student groups at low-cost. Unlike existing mobile and wireless learning technologies, our approach is designed to support resource poor areas in South East Asia and diverse student cohort and evaluated in South East Asian context. The new learning environment is particularly suitable for developingcountries, where limited learning space or no proper wireless network services are available. DSL can be adjusted based on the different requirements. Furthermore, MCEL can be operated on conventional inexpensive GSM mobile services to provide personalized learning experiences. Unlike previous approaches, MCEL uses automated tutoring system that are customisable by teachers in order to reduce the cost of education. In many resource poor areas in South East Asia, this is particularly important and will have significant impact in improving access to education.

\section{$7 \quad$ References}

[1] Devlin, M. (2012). Non-traditional student achievement: Theory, policy and practice in Australian higher education. Paper presented at the FYHE 2010: Aspiration, Access, and Achievement: Proceedings of the 13th Pacific Rim First Year in Higher Education Conference 2010.

[2] Lefoe, G. E., \& Hedberg, J. (2006). Blending on and off campus: A tale of two cities.

[3] McInnis, C., \& Hartley, R. (2002). Managing study and work: The impact of full-time study and paid work on the undergraduate experience in Australian universities.

[4] Sharpe, R., Benfield, G., Roberts, G., \& Francis, R. (2006). The undergraduate experience of blended e learning: a review of UK literature and practice: Higher Education Academy London.

[5] Conole, G. (2004). E-learning: The hype and the reality. Journal of Interactive Media in Education, 11. https://doi.org/10.5334/2004-12 
[6] Smith, S. L., \& Walters, A. (2012). Mobile Learing: Engaging today's hospitality students. Journal of Hospitality \& Education, 24(2-3), 45-49. https://doi.org/10.1 $\underline{080 / 10963758.2012 .10696669}$

[7] Zhang, B., Looi, C.-K., Seow, P., Chia, G., Wong, L.-H., Chen, W. Norris, C. (2010). Deconstructing and reconstructing: Transforming primary science learning via a mobilized curriculum. Computers \& Education, 55(4), 1504-1523. https://doi.org/10.1016/j.compedu.2010.06.016

[8] Ting, Y. L. (2013). Using mobile technologies to create interwoven learning interactions an intuitive design and its evaluation. Computers \& Education, 60(1), 113.https://doi.org/10.1016/j.compedu.2012.07.004

[9] Song, Y. J., Wong, L. H., \& Looi, C. K. (2012). Fostering personalized learning in science inquiry supported by mobile technologies. Etr\&D-Educational Technology Research and Development, 60(4), 679-701. https://doi.org/10.1007/s11423-012-9245$\underline{6}$

[10] Barrow-Britton, D., \& Geddie, M. W. (2004). Creating community and collaboration online: How to be a distance instructor without becoming a distant instructor. Journal of Hospitality \& Education, 16(3), 26-31 https://doi.org/10.1080/10963758.2004.10696798

[11] Boticki, I., Wong, L. H., \& Looi, C. K. (2013). Designing Technology for ContentIndependent Collaborative Mobile Learning. Ieee Transactions on Learning Technologies, 6(1), 14-24. https://doi.org/10.1109/TLT.2012.8

[12] Brown, A. L. (1992). Design experiments: Theoretical and methodological challenges in creating complex interventions in classroom settings. The Journal of the Learning Sciences, 2(2), 141-178. https://doi.org/10.1207/s15327809j1s0202 2

[13] Bloom, B. S. (1956). Taxonomy of educational objectives: The classification of education goals by a committee of college and university examiners: David McKay.

[14] Bloom, B. S. (1971). Handbook on formative and summative evaluation of student learning.

[15] Krathwohl, D. R. (2002). A revision of Bloom's taxonomy: An overview. Theory into practice, 41(4), 212-218. https://doi.org/10.1207/s15430421tip4104 2

[16] Anderson, L. W., Krathwohl, D. R., Airiasian, W., Cruikshank, K., Mayer, R., \& Pintrich, P. (2001). A taxonomy for learning, teaching and assessing: A revision of Bloom's Taxonomy of educational outcomes: Complete edition: New York: Longman.

[17] Anderson, L. W., Krathwohl, D. R., \& Bloom, B. S. (2005). A taxonomy for learning, teaching, and assessing: Longman.

[18] Kolb, D. A. (1984). Experiential learning: Experience as the source of learning and development (Vol. 1): Prentice-Hall Englewood Cliffs, NJ.

[19] Hedin, B. O. (2006). Mobile message services using text, audio or video for improving the learning infrastructure in higher education. International Journal of Emerging Technologies in Learning (iJET), 1(1).

[20] Biggs. J. B. \& Collis. K. F. (1982) Evaluating the Quality of Learning: The Solo Taxonomy Academic Press, New York. Ramsden, P. (1997). The context of learning in academic departments. The experience of learning, 2, 198-216.

[21] Bybee, R. (1997). Achieving scientific literacy: From purposes to practical action. Portsmouth, NH.

[22] Hackling, M., Peers, S., \& Prain, V. (2007). Primary Connections: Reforming science teaching in Australian primary schools. 
[23] Chu, S. K. W., Reynolds, R. B., Tavares, N. J., Notari, M., \& Lee, C. W. Y. (2017). 21st century skills development through inquiry-based learning: From theory to practice. Singapore: Springer Singapore. https://doi.org/10.1007/978-981-10-2481-8

[24] Beetham, H., \& Sharpe, R. (2013). Rethinking Pedagogy for a Digital Age: Designing for 21st Century Learning: routledge.

[25] Sharpe, R., Beetham, H., \& Freitas, S. d. (2010). Rethinking learning for a digital age: Routledge Oxfordshire.

[26] Mueller, J., Wood, E., De Pasquale, D., \& Cruikshank, R. (2012). Examining Mobile Technology in Higher Education: Handheld Devices In and Out of the Classroom. International Journal of Higher Education, 1(2). https://doi.org/10.5430/ijhe.v1n2p43

[27] Hsu, L., \& Lee, S.-N. (2011). Learning English on mobile phones: How does it work? The Journal of Hospitality Leisure Sport and Tourism, 10(2), 85-94. doi:10.3794/johlste.102.348 https://doi.org/10.3794/johlste.102.348

[28] Ross, S. M., Morrison, G. R., \& Lowther, D. L. (2010). Educational Technology Research Past and Present: Balancing: Rigor and Relevance to Impact School Learning. Contemporary Educational Technology, 1(1).

[29] Maldonado, N., \& Morgan, H. (2010). Technology in the Classroom: Using Handheld Wireless Technologies in School: Advantageous or Disadvantageous? Childhood Education, 87(2), 139-142. https://doi.org/10.1080/00094056.2011.10521462

[30] Koh, E., Kin, Y. G., Wadhwa, B., \& Lim, J. (2012). Teacher perceptions of games in Singapore schools. Simulation \& Gaming, 43(1), 51-66. https://doi.org/10.1 $\underline{177 / 1046878111401839}$

[31] Tay, L. Y., Lim, C. P., Lye, S. Y., Ng, K. J., \& Lim, S. K. (2011). Open-source learning management system and Web 2.0 online social software applications as learning platforms for an elementary school in Singapore. Learning, Media and Technology, 36(4), 349-365. https://doi.org/10.1080/17439884.2011.615322

[32] Gay, G., Stefanone, M., Grace-Martin, M., \& Hembrooke, H. (2001). The effects of wireless computing in collaborative learning environments. International Journal of Human-Computer Interaction, 13(2), 257-276. https://doi.org/10.12 07/S15327590IJHC1302 10

[33] Salter, D., Thomson, D. L., Fox, B., \& Lam, J. (2013). Use and evaluation of a technology-rich experimental collaborative classroom. Higher Education Research \& Development, 32(5), 805-819. https://doi.org/10.1080/07294360.2013.777033

[34] Kneebone, R., \& Brenton, H. (2005). Training perioperative specialist practitioners. Mobile Learning: A handbook for educators and trainers, Routledge, Milton Park, 106115.

[35] Kramer, M. (2009). Deciphering the future of learning through daily observation. Paper presented at the 3rd Mobile Learning Symposium, WLE Centre, IOE London, UK.

[36] Coulby, C., Hennessey, S., Davies, N., \& Fuller, R. (2011). The use of mobile technology for work-based assessment: the student experience. British Journal of Educational Technology, 42(2), 251-265. https://doi.org/10.1111/j.1467$\underline{8535.2009 .01022 . \mathrm{x}}$

[37] Alon, I., Jones, V., \& McIntyre, J. R. (2013). Innovation in business education in emerging markets. https://doi.org/10.1057/9781137292964

[38] Norris, C., \& Soloway, E. (2008). Getting mobile handhelds help bring K-12 classrooms into the 21st century. District Administration Magazine, Professional Media Group, LLC, CT. Available at: http://www. District administration. com/(last accessed 20 October 2016). 
[39] Jones, A., \& Issroff, K. (2007). Motivation and mobile devices: exploring the role of appropriation and coping strategies. Research in Learning Technology, 15(3). https://doi.org/10.3402/rlt.v15i3.10934

[40] Laurillard, D. (2007). Pedagogical forms of mobile learning: framing research questions.

[41] Schank, R. C., Fano, A., Bell, B., \& Jona, M. (1994). The design of goal-based scenarios. The Journal of the Learning Sciences, 3(4), 305-345. https://doi.org/10.1 207/s15327809jls0304 2

[42] Ouyang, C., Dumas, M., Breutel, S., \& Hofstede, A. (2006). Translating standard process models to BPEL. Paper presented at the Advanced Information Systems Engineering. https://doi.org/10.1007/11767138 28

[43] Roche, E., \& Schabes, Y. (1997). Finite-state language processing: The MIT Press.

[44] Manning, C. D., \& Schütze, H. (1999). Foundations of statistical natural language processing (Vol. 999): MIT Press.

[45] Parr, T. (2007). The definitive ANTLR reference: Building domain-specific languages: Pragmatic Bookshelf.

[46] Hardyman, W., Bullock, A., Brown, A., Carter-Ingram, S., \& Stacey, M. (2013). Mobile technology supporting trainee doctors' workplace learning and patient care: an evaluation. Bmc Medical Education, 13-https://doi.org/10.1186/1472-6920-13-6

[47] Ellaway, R. (2010). Apples and architraves: a descriptive framework for e-learning research. Medical teacher, 32(1), 95-97. https://doi.org/10.3109/01421590903573966

[48] David, B. T., Yin, C., \& Chalon, R. (2007). Contextual mobile learning for appliance mastery. Proceedings of Mobile Learning 2007, 3-10.

[49] James, P. T. (2011). Mobile-Learning-Thai HE Student Perceptions and Potential Technology Impacts. International Education Studies, 4(2), p182. https://doi.org/10 $.5539 /$ ies.v4n2p182

[50] Denzin, N. K., \& Lincoln, Y. S. (2011). The SAGE handbook of qualitative research: Sage.

[51] Rakic, T., \& Chambers, D. (2010). An introduction to visual research methods in: Routledge, Taylor \& Francis.

[52] Bhati, A., \& Pearce, P. (2016). Vandalism and settings: an integrative review.

[53] Biggs, J., \& Tang, C. (2011). Teaching for quality learning at university: Open university press

\section{Authors}

Abhishek Bhati is the Campus Dean and Associate Professor at JCU Singapore. $\mathrm{He}$ is the Head of learning, teaching and student engagement. His research interest is in student experience and sustainable tourism development. Email id: Abhishek.bhati@jcu.edu.au

Insu Song is a Senior Lecturer at JCU Singapore. Dr Song was awarded a prestigious international grant from Bill and Melinda Gates foundation to work on mobile applications for providing "Early Child Health Intervention Using Breathing Sound."

Article submitted 2018-07-07. Resubmitted 2018-09-04. Final acceptance 2018-09-07. Final version published as submitted by the authors. 